\title{
“DIGAS O QUE CONSOMES QUE TE DIREI QUEM ÉS": FATORES QUE INFLUENCIAM NO PADRÃO DE CONSUMO E QUE CONFIGURAM O PERFIL DO CONSUMIDOR ATUAL
}

"Say what consume l'll tell you who you are": factors that influence the consumption pattern and that shape the profile of the current consumer

\section{Sílvia Naiara de Souza Borba'}

'Universidade Federal do Rio Grande do Sul (UFRGS) - Aluna de mestrado do Programa de Pós-graduação em Desenvolvimento Rural. E-mail: silvianaiara@hotmail.com;

\begin{abstract}
Resumo
A ênfase dirigida à alimentação no decorrer das últimas décadas tem motivado medidas e transformações neste campo, incidindo inclusive, no posicionamento dos consumidores. O objetivo do ensaio teórico é identificar alguns fatores que influenciam na mudança dos padrões de consumo, principalmente, na procura por alimentos alternativos. No primeiro momento, são abordados fatores mais ligados ao avanço tecnológico nas práticas de produção e suas implicações na saúde. Na segunda parte, entra-se no mérito de "enraizamento", entendendo a dinâmica de valorização de produtos e interligando-o com o local de origem e atributos de qualidade. O último fator relaciona esta mudança dos padrões de consumo a uma sociedade que preza a sua satisfação e encontra no consumismo uma forma de renovar sua identidade. Após o resgate desses fatores, conclui-se que há necessidade de investigar os consumidores de produtos diferenciados produzidos no meio rural, visto que a partir deste ponto algumas políticas de apoio governamental aos pequenos agricultores podem ser reformuladas ou talvez implementadas de acordo com a característica dos determinados locais e demandas.
\end{abstract}

Palavras-chave: consumidor, padrão de consumo, enraizamento, saúde.

\begin{abstract}
The emphasis directed to food in the last decades has motivated measures and transformations in this field, including focusing on consumer positioning. The objective of this theoretical essay is to identify some factors that influence the changing patterns of consumption, mainly in the search for alternative foods. At first, most are addressed factors related to technological advances in production practices and their health implications. The second part goes on the merit of "embeddedness", understanding the dynamics of recovery of products and connecting them to the place of origin and quality attributes. The final factor relates the change in consumption patterns to a society that values your satisfaction and consumerism is a way to renew their identity. After the rescue of these factors, it is concluded that there is a need to investigate consumers of differentiated products produced in rural areas, since from this point some policies of government support to small farmers can be reformulated or maybe implemented in accordance with the characteristic of certain locations and demands.
\end{abstract}

Keywords: consumer, consumption pattern, "embeddedness", health. 


\section{INTRODUÇÃO}

As preocupações com a segurança e qualidade dos alimentos levam muitos consumidores a ter mais cuidado com seus hábitos de consumo, tornando a qualidade sinônimo de local ou de alimentos naturais (WISKERKE, 2010).

Esta é uma das perspectivas que tem provocado alteração nos padrões alimentares da população, visto que, por exemplo, no Brasil com a chegada dos produtos orgânicos no mercado, mais especificamente frutas, legumes e verduras, a mudança no consumo foi percebida pela crescente demanda a estes artigos. A procura tornou-se constante até os dias atuais, o que poderia ser considerado uma "moda", algo que sofre obsolescência e que cai no esquecimento das pessoas, ainda tem sua representatividade e valoração. Isso não significa que esse ponto de vista não se constitua no pensamento de alguns. Segundo Portilho et al. (2011), os anos noventa representam uma virada histórica na alimentação como campo político, os riscos e a dimensão de natureza da comida são algumas das principais facetas politizadoras dos estudos contemporâneos sobre a alimentação.

Nichos diferenciados tem incitado o consumidor a exigir alimentos que sejam "limpos", livres de qualquer resíduo, seja químico, físico ou biológico. A preocupação com a saúde tem sido propulsora nesta busca. Todavia, existe outro viés que pode influenciar o consumo destes alimentos alternativos, como prática de mudança alimentar, a preocupação com as questões ambientais e o estímulo a práticas de produção sustentável, já que as formas tradicionais estariam causando a escassez dos recursos naturais não renováveis.

Pode-se chegar assim, em diferentes hipóteses que explicam essa mudança de perfil dos consumidores e a demanda por feiras livres, supermercados que forneçam produtos sejam eles orgânicos ou que possuam referência na sua origem. Ressalta-se que as características de consumidor de um lugar e outro apresentam peculiaridades. O conhecimento acerca do perfil deste público pode vir a ganhar um importante espaço dentre as estratégias para a promoção do desenvolvimento no meio rural, pois a partir do momento que surgem demandas específicas, há um maior escoamento da produção, além de adaptações que poderão ser feitas para a diferenciação dos produtos. Seguindo essa linha de raciocínio, outra hipótese aparece, tais mudanças alimentares se efetivaram a partir de uma organização local, que com impulso externo teria desencadeado o processo de "enraizamento", a valorização de produtos intrínsecos as localidades, sendo legitimadas e adquirindo visibilidade perante o público consumidor através de vários atores.

Além da preocupação com riscos a saúde, incentivo e integração de atores compondo o mesmo local, a necessidade de consumo que configura a sociedade pós-moderna que Bauman retrata, poderia ser um dos fatores que implica na forma como os consumidores classificam e optam pelos alimentos. Além dos orgânicos, o respaldo e incentivo a produção valorizando a cultura, os saberes tradicionais e o respeito aos recursos naturais, são características de iniciativas locais, despertando no consumidor a necessidade de contato com os agricultores e informações de procedência de cada item.

De acordo com as diferentes abordagens, este ensaio teórico tem como objetivo identificar alguns fatores que influenciam na mudança dos padrões de consumo, principalmente, a procura por alimentos alternativos.

\section{INTERFACES NA MUDANÇA DOS PA- DRÕES ALIMENTARES}

\section{I Preocupações com a Saúde: Um motivador na procura por orgânicos}

No início dos anos noventa, inicia uma forte discussão que envolveu a sociedade como um todo, o uso de agrotóxicos associado com a contaminação em alimentos. O foco das discussões remetia aos resíduos químicos encontrados nos alimentos e que através da ingestão, o efeito cumulativo desses contaminantes no organismo, traria consequência para a saúde do indivíduo. Outras percepções visavam discutir, inclusive, os impactos negativos e desequilíbrios que esses agrotóxicos trariam para o ambiente, fauna e flora. As implicações do contato do agricultor com estes defensivos permaneceram menos evidentes, todavia a preocupação com a alimentação causou uma busca por alimentos alternativos, que fossem inócuos. A visibilidade para os produtos tradicionais, que valorizam o local, expandiu-se principalmente, pela procura por qualidade e segurança do alimento.

No setor de frutas, legumes e verduras, a procura por orgânicos passou a se consolidar e se mantêm nesta condição até os dias atuais. Os atores envolvidos no processo de transição da agricultura convencional para uma agricultura sustentável almejam mudanças em nível social, 
econômico, político e global, onde a produção seja descentralizada e estabeleça novos valores para a produção e consumo (GUIVANT, 1993).

Em seu artigo intitulado "Reflexividade na sociedade de risco: conflitos entre leigos e peritos sobre os agrotóxicos", Guivant (2000) problematiza o uso de agrotóxicos e os seus riscos. De um lado, parte da comunidade científica alega que os riscos só existem porque os indivíduos que manipulam os agrotóxicos não seguem os níveis recomendados, de outro lado, os riscos são relacionados a doenças que o ser humano poderá estar desencadeando, até mesmo transmitindo à outras gerações na forma de mutações gênicas. Além disso, são discutidos os riscos dos agrotóxicos associados ao desequilíbrio ambiental, eventos como a resistência aos agrotóxicos e proliferação excessiva de pragas.

Guivant sugere que uma das alternativas para evitar este uso seria "pressões de consumidores mais reflexivos", preocupados com sua saúde e com o meio ambiente. O uso recomendado de agrotóxicos é uma ficção para os agricultores, e os efeitos de suas doses não desaparecerão. Há muitos riscos previsíveis decorrentes dos agrotóxicos, mas que não são observados em laboratório quando fabricados e testados (GUIVANT, 2000).

Beck e Giddens apud Guivant (2000) acreditam que a ciência e a tecnologia deveriam incorporar outros moldes, pois a partir do momento que estabelecem níveis de aceitabilidade de uso, no caso dos agrotóxicos, ignoram seus impactos no meio ambiente e para a saúde humana. Neste caso, os problemas gerados são tratados meramente como efeitos colaterais. Esses autores acreditam que muitos riscos são oriundos principalmente do surgimento desses agrotóxicos, desencadeando a crise ecológica atual, resultante de ações humanas e concebidas pela ciência. Para consolidar esta afirmação Laurent (Informação verbal) ${ }^{1}$ ao explanar sobre as formas de desenvolvimento da agricultura e alimentação retratando desde a escala global até a local evidencia que:

Na Bacia do Oudon na França a área agrícola cobre $87 \%$ da Bacia do rio e as poluições encontradas nele são de origem agrícola: nitrato, fósforo e pesticida. Este cenário se configurou em uma ameaça à utilização desta água para o abastecimento humano. Visto isso, para reduzir a polui-

\footnotetext{
${ }^{1}$ Palestra ministrada por François Laurent, professor em Geografia na Université du Maine (Le Mans, France) no Programa de Pós-Graduação em Desenvolvimento Rural (PGDR) com a seguinte proposta: Formas de desenvolvimento da agricultura e a alimentação: da escala internacional à escala local, Porto Alegre, agosto de 2013.
}

ção, no Oudon, o Governo Francês impôs limites a fertilização, passou de 150/190 $\mathrm{KgN} /$ ha para $140 \mathrm{KgN} / \mathrm{ha}$. Outra medida foi o incentivo a substituição de milho por pastagens nesses locais, disponibilizando o valor aproximado de 200 euros/ha/ano para o agricultor que fizesse essa troca (LAURENT, 2013).

Giddens (1998) acredita que uma atual mudança no sistema político, através do reconhecimento irredutível dos riscos, possa gerar um ambiente ético de responsabilidade individual e coletivo. A autora atribui um papel central aos movimentos sociais e aos consumidores na luta de redução de riscos. Desta maneira, as pressões que podem emergir das preferências dos consumidores se manifestam como fundamentais para mudar as práticas agrícolas (GUIVANT, 1993).

Beardsworth e Keil (1997) apud Guivant (2000) referenciam pesquisas na Suécia e nos Estados Unidos que apontam como as opiniões dos leigos sobre os riscos dos alimentos tendem a ir em direção oposta a dos peritos. Enquanto estes últimos colocavam no topo da lista de riscos alimentares, gorduras, açúcar e sal, os consumidores leigos se preocupavam mais com substâncias como mercúrio e metais pesados, seguidos de pesticidas e bactérias, e colocando gorduras, açúcar e sal no final da lista.

Outro fator que merece ser destacado nesta busca por alimentos alternativos, é a característica do consumidor e o local que este recorre para adquirir os produtos. De acordo com Guivant (2003) o "boom" dos orgânicos no início dos anos noventa fez com que os supermercados tivessem prioridade na venda deste segmento, atribuindo aos canais alternativos o papel secundário na oferta desses produtos. A autora classifica a demanda por produtos orgânicos como definida e difusa, acredita que o perfil dos consumidores que frequentam lojas especializadas se configure no primeiro caso e aqueles que procuram por orgânicos em supermercados se enquadrem no segundo caso. Portanto, verifica-se uma mudança em relação ao consumo e consequentemente posicionamento distinto entre consumidores e seus mecanismos de escolha por alimentos com tal característica. Guivant argumenta que a crescente demanda de produtos orgânicos em supermercados, se reflita na procura pelo consumidor por alimentos saudáveis, configurando-se em um estilo de vida denominado ego-trip, em contraste com o ecológico-trip (GUILLON; WILLIQUET, 2003 
apud GUIVANT, 2003).

A autora supracitada, munida de tais informações, conclui que os indivíduos não estariam avaliando continuamente suas decisões de consumo, mas fadados e conscientes de que estão fazendo uma escolha. Os consumidores que adotam os orgânicos como estilo de vida mais saudável, (ego-trip), não sopesam as práticas sociais como componentes do processo, não consideram as ações de comprometimento com o ambiente. Já os ecológico-trip, visam a responsabilidade social ao optarem pelo consumo de orgânicos.

No artigo "Os supermercados na oferta de alimentos orgânicos: apelando ao estilo de vida ego-trip" Guivant afirma que para tornar o consumidor fiel, os supermercados investem em quantidade e variedade dos produtos orgânicos, além de adequar os produtos às características do local, uma estratégia de marketing utilizada. Diante dessa característica, pode-se resgatar o fator identidade como um determinante na mudança de hábito alimentar, relacionado inclusive com a cultura.

Guivant (2003) cita um estudo realizado com a população Americana com Hartman Group em 2000, "The Wellness Lifestyle Shopper: Mapping the Journeys of Wellness Consumers", onde "a preocupação com a saúde e a qualidade nutricional dos alimentos foi citada por $66 \%$ dos consumidores orgânicos entrevistados em tal pesquisa. O conhecimento dos riscos dos pesticidas foi a razão dada por $38 \%$, segurança alimentar por $30 \%$, enquanto razões ambientais foram mencionadas apenas por $26 \%$ dos consumidores, contradizendo a crença de que os consumidores de alimentos orgânicos são conscientes ambientalistas". Deste modo, a autora chama a atenção para um perfil de consumidor que não está preocupado com os movimentos sociais, ativistas ou pessoas que acreditam em responsabilidade social, mas sim consumirem estes produtos e serem considerados "reflexivos" por serem instruídos pela mídia.

As evidências retratadas até então, chamam a atenção para uma migração de um sistema alimentar centrado em tecnologias convencionais para um que prima por formas de produção alternativas, atendendo a um público que procura por alimentos limpos e de qualidade. Neste processo de mudança, alguns perfis vão se delineando, e a partir desta identificação podem-se criar cenários e tendências de consumo. Estas informações quando traduzidas para o rural, configuram-se em ferramentas de desenvolvimento local.

\section{INTERAÇÃO PRODUTO, PROCESSO E LUGAR: UMA NOVA PROPOSTA DE CON- FIGURAÇÃO DOS SITEMAS ALIMENTARES}

O sistema agroalimentar vigente estabelece um distanciamento entre produção dos alimentos e o consumo, seja por requisitos normativos ou pelo processo de beneficiamento do produto e valor agregado privilegiando a indústria. De acordo com Ilbery (2005), a reconexão dos consumidores com os produtores de alimentos gera uma relação de confiança entre ambos. Para haver a reconexão, é preciso que os produtos ofertados possuam diferenciais, que sejam distintos daqueles produzidos em massa, e que possuam como requisito fundamental a qualidade. Os produtos alimentares devem sair do anonimato, sendo identificados por sua procedência, especificidade territorial e forma de produção (ILBERY, 2005).

$\mathrm{Na}$ medida em que a identidade territorial de uma região é especificada em um produto, gera uma responsabilidade de ordem social, econômica e ambiental, facilitando inclusive a comercialização do mesmo. Ilbery (2005) reforça a ideia da interação entre produto, processo e lugar como sendo ingredientes essenciais para o desenvolvimento rural e territorial. Outra forma de interação se dá entre os produtores locais que formam associações visando agrupar quantidades significativas de produtos e facilitar o escoamento dos mesmos, além de reafirmar questões ambientais ligadas a cada região de produção.

O processo de "enraizamento" delineado por Ilbery, leva em consideração as potencialidades de determinados locais, que, associados aos incentivos e a forma com que são propostos, interligam atores e promovem o desenvolvimento. $\mathrm{O}$ apoio de alguns órgãos visando iniciativas locais, no que diz respeito a produção de alimentos saudáveis ou que preservam a identidade de cada região ou território, pode ter impulsionado o consumidor a ser mais reflexivo, valorizando esta forma de produção e modificando o cenário que vislumbra os alimentos. A qualidade dos alimentos ganha espaço na discussão e segundo um estudo feito por Ilbery e Kneafsey (2000), os consumidores atribuem significação aos atributos alimentares representados pelo design, textura, flavour, sabor, aparência e preços. Ainda de acordo com estes autores:

Apesar de útil como uma ferramenta de análise, estes indicadores são construídos socialmente e isso levanta uma segunda 
questão conceitual importante sobre a qualidade. Esta é de fato uma construção social e, portanto, dependente dos contextos socioculturais, políticas e econômicas dentro das quais existem relações de produção e consumo (ILBERY; KNEAFSEY, 2000, p. 219).

Esta construção de significados e atribuição de valores aos produtos locais, transformando-os em nichos de mercado, com vistas à proteção de conhecimentos tradicionais, faz com que também desencadeie um novo perfil de consumidor e consequentemente uma mudança no padrão de consumo. Salientar a importância de conhecimento destes perfis impactará em novas estratégias para determinadas regiões. Como aponta Ilbery e Kneafsey (2000) o Comitê das Regiões da União Europeia em 1996, por exemplo, reconheceu a promoção de nichos de mercado para produtos regionais como um mecanismo potencial para impulsionar o desenvolvimento socioeconômico em áreas rurais periféricas. Na figura 1. é possível identificar a relação entre produto, processo e lugar que Ilbery menciona ao referir-se ao processo de integração e "enraizamento" com estimas ao desenvolvimento territorial.

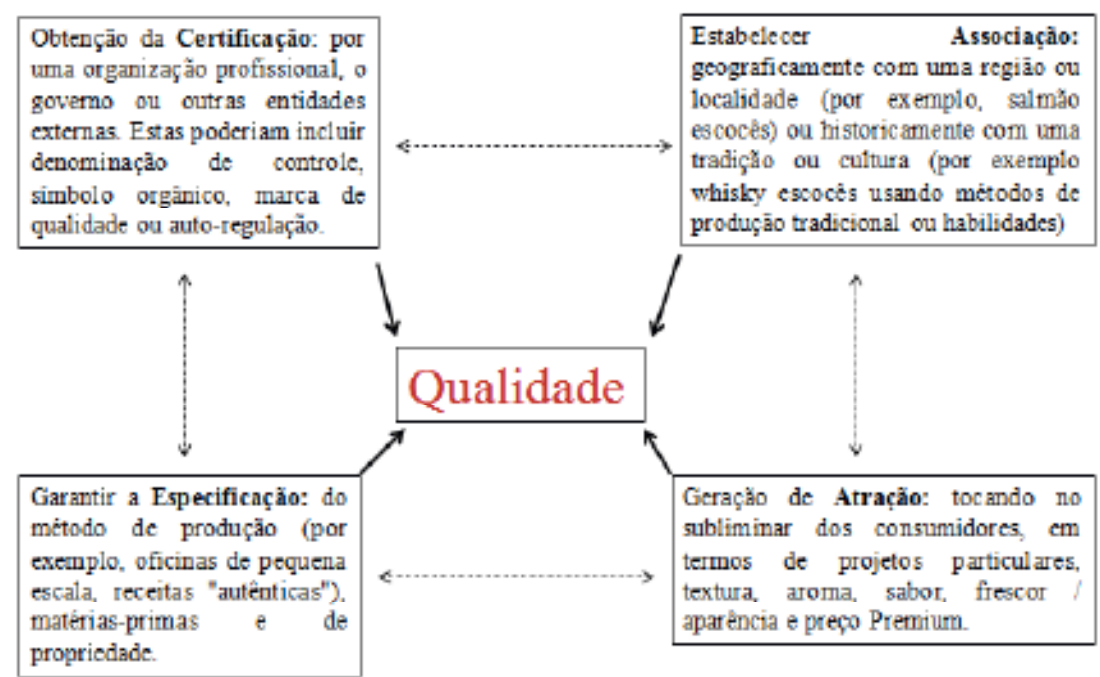

Figura 1. Conceituação de qualidade

Fonte: Ilbery e Kneafsey (2000) /Traduzido pela autora

De acordo com Miele (2006), as perspectivas que permeiam o consumo de alimentos são discutidas sob uma ótica cultural específica em diferentes locais e aspectos, afetados por: alteração nas preferências alimentares, hábitos alimentares e repertórios de culinária individuais que oferecem bom acesso a comida e possibilidades de escolha. A proposta de Ilbery, que visa integrar os produtos, processos e locais de produção, é promotora de mudança nos hábitos alimentares, pois movimenta todo o panorama que circunda tais iniciativas, a fim de conscientizar e reeducar as pessoas para $o$ reestabelecimento da sua cultura alimentar.

Quando se associa o surgimento de redes agroalimentares alternativas à características intrínsecas ao alimento, Goodman (2003) faz referência a virada da qualidade, onde o mesmo compara a literatura norte americana e europeia e chega a conclusão de que, embora haja diferenças entre as intenções que consolidaram estas redes nestas nações, evidências que convergem referem-se a novas formas organizacionais como portadores de mudanças políticas transformadoras e torna-se um modelo institucional alternativo de desenvolvimento rural.

\section{REFLEXOS DE UMA SOCIEDADE INDIVI- DUALIZADA}

A avaliação de uma sociedade pós-moderna tenta imprimir o quanto ela pode estar influenciando em mudanças de padrão de beleza, de vestuários e inclusive na alimentação em virtude das consequências históricas do período anterior.

Ao fazer uma análise da obra Modernidade Líquida de Bauman, Cugini (2008) dá ênfase á uma mudança nos valores da sociedade, passando de sociais para individuais, o interesse próprio é um motivador para desempenhar funções ou 
tarefas, não interessando as demandas coletivas. Acrescendo essas informações e sintonizando à Bauman, o mundo líquido exige dos indivíduos uma constante mudança de hábitos. Quando se refere a identidade, no mundo pós-moderno é necessário que esta seja líquida também, todavia torna-se vulnerável e passível de fragilidades e apropriações. Em uma sociedade de consumidores, as pessoas preferem evitar os encontros face a face, optando cada vez mais por mecanismos virtuais, a fim de diminuir riscos e imprevistos. Esta é uma característica que os grandes impérios alimentares se apropriam e a torna estratégia de marketing na oferta de alimentos instantâneos, padronizados e ofertados em máquinas que operam sozinhas.

A subjetividade na sociedade de consumidores está na condição de esquecimento ou condenação devido às origens humanas, passíveis de negociação na construção de identidades através de símbolos (BAUMAN, 2008). A busca incessante pela identidade, também está relacionada à alimentação, associada a um contexto de indivíduos que hora apresentam características de individualismo e comportamento antissocial e hora procuram nichos de mercado diferentes para reforçarem sua posição na sociedade. Bauman faz a distinção entre o consumismo e o consumo, atribuindo ao primeiro uma característica oriunda da sociedade e o segundo, respectivamente, proveniente da ocupação dos seres humanos como indivíduos. Para Miele (2006), alimentos e bebidas tem se tornado símbolos de posição e status social nas análises da Sociologia e se tornaram visíveis nos estudos sobre o consumo.

A necessidade de consumir além das demandas convencionais, faz com que o consumismo assuma alguns papéis nesta sociedade, considerada por Bauman como pós-moderna. A intenção não é satisfazer plenamente os consumidores, mas, gerar um sentimento de vazio a ser preenchido a qualquer instante por uma mercadoria que substitua a anterior. Este quadro nos confronta com um fenômeno denominado de obsolescência programada, onde os bens são produzidos com baixa expectativa de funcionamento e vida útil. O propósito é vender em massa, gerar receita nas multinacionais e alavancar a economia. Bauman (2008, p. 63), deixa claro essa ideia e ainda nos direciona para outra conclusão, a de que as mudanças no sistema alimentar também foram frutos das consequências do consumismo, na construção e consolidação de impérios de alimentos.

Assim como os "trabalhadores tradicionais" fáceis de satisfazer - que não concordariam em trabalhar mais do que o necessário para garantir a permanência do modo de vida habitual - eram o pesadelo da nascente "sociedade de produtores", da mesma forma os "consumidores tradicionais" - guiados pelas necessidades familiares de ontem, fechando com alegria os olhos e tapando os ouvidos aos afagos do mercado de bens de consumo para poderem seguir suas velhas rotinas e manter seus hábitos - significaria o dobre de finados da sociedade de consumidores, da indústria de consumo e dos mercados de bens... [são esses os mais temidos adversários da economia orientada para o consumidor e que, portanto, devem ser relegados ao esquecimento (BAUMAN, 2008, p. 63).

O autor supracitado também atribui a busca pelo prazer, o papel de estimular o isolamento dos indivíduos na busca por interesses próprios. Todavia, ao imprimir este cenário, especificamente, no campo da alimentação, observa-se uma tendência oposta aos argumentos apresentados por Guivant. Esta acredita que a procura por alimentos diferenciados ocorre devido a preocupações com relação a saúde, evidenciado na demanda por orgânicos, por exemplo. Em contrapartida, se analisarmos pelo viés do "prazer", o consumo se dá para uma satisfação pessoal, ignorando ou desconhecendo, em muitos casos, as propriedades que garantiriam a segurança física, química ou biológica do alimento.

Ao tratar do assunto repetição como sendo um fator de predisposição da neurose, Giddens (1997) observa que a sociedade com espírito capitalista é hedonista, apresentando dependência de substâncias que causam prazer como drogas, álcool, café, esporte e não seria diferente com a alimentação. Para Giddens (1997) os "vícios ingestivos" antes de serem fatores psicológicos, são fenômenos sociais. Em complemento, Fortes $(2009$, p. 1127) acrescenta que "a cultura do hedonismo está intrinsecamente associada à sociedade do consumo".

As análises são amplas ao entrar no campo das causas que motivam mudanças nas arenas alimentares, é preciso saber identificar os consumidores para saber quais são suas prioridades e necessidades ao dirigirem-se aos centros de consumo. Quando se refere a novas "tribos pós-modernas", Miele (2006) identifica a individualização como característica de novos grupos de consumo, o que gera novos grupos sociais com novas demandas. 


\section{CONCLUSÕES}

Ao concluir o ensaio, constata-se que no Brasil principalmente, há uma carência de literatura que estude os consumidores dos produtos procedentes do meio rural e que possuem diferenciais em seu processo produtivo. Ressaltando que não é somente estudar as técnicas de marketing desses nichos, mas aprofundar a leitura nos fatores que motivam o consumidor e qual o objetivo de suas escolhas na procura por alimentos alternativos. A compreensão da sociedade talvez seja uma forma de desencadear processos promotores de desenvolvimento em áreas menos favorecidas, além disso, realizar um apelo na mantença da biodiversidade no processo de produção de alimentos. Na maioria das vezes, o principal alvo das pesquisas são os estudos de caso, explorando e evidenciando informações valiosas, mas que ficam restritas a determinados pontos.

Um componente que leva o consumidor a optar por produtos alternativos ao convencional é a confiança que se estabelece entre produtor e consumidor, na medida em que ocorre o encurtamento da cadeia de abastecimento. A possibilidade de identificar a origem e detalhes da produção, as trocas de experiências e o resgate de saberes de uma determinada cultura ou local são as consequências benéficas de interligar produtos, produtores e consumidores num espectro de confiança. O desafio é lançar mão de metodologias e teorias que possam ser aplicadas e constatadas, respectivamente, com o intuito de chegar a um perfil de consumidor, tentando na medida do possível, compreender o grau de reflexividade perante as desordens ocorridas no campo da alimentação. Visto que há um posicionamento quando optam por alimentos alternativos. Será que a reflexividade tem como quesito fundamental o nível de risco associado à saúde? É delimitada pela confiança no local como sinônimo de qualidade? Ou é sinônimo de escape na busca de uma identidade líquida? Talvez a resposta para estes questionamentos e a busca de influências no padrão de consumo, seja a soma de todas estas associadas a fatores ainda não abordados em pesquisas.

\section{REFERÊNCIAS}

BAUMAN, Z. Vida para consumo: a transformação das pessoas em mercadoria. Tradução: Carlos Alberto Medeiros. Rio de Janeiro: Zahar, 2008.
BECK, U. Politics Of Risk Society. In: Franklin, Jane (Org.). The Politics Of The Risk Society. Cambridge: Polity Press, 1998.

CUGINI, P. Identidade, afetividade e as mudanças relacionais na modernidade líquida na Teoria de Zygmunt Bauman. Diálogos possíveis. Bahia, jan./ jun. 2008.

FORTES, I. A psicanálise face ao hedonismo contemporâneo. Mal-estar e subjetividade. Fortaleza, v. 9, n. 4, 2009.

GOODMAN, D. The quality 'turn' and alternative food practices: reflections and agenda. Journal of Rural Studies, v. 19, p.1-7, 2003.

GIDDENS, A. "A vida em uma sociedade pós-tradicional", In: BECK, Ulrich; GIDDENS, Anthony; LASH, Scott. (Orgs). Modernização reflexiva, São Paulo: Ed. da Unesp, 1997.

GUIVANT, J. Reflexividade na sociedade de risco: conflitos entre leigos e peritos sobre os agrotóxicos. In: HERCULANO, Selene. (Org.). Qualidade de vida e riscos ambientais. Niterói: Editora da UFF, 2000.

GUIVANT, J. Parâmetros teóricos para a análise da difusão e adoção de uma agricultura sustentável. In: VIEIRA, P.F.; MAIMON, D. (Org.). As ciências sociais e a questão ambiental rumo a interdisciplinariedade. Belém do Pará: Aped Editora/Naea, 1993.

GUIVANT, J. Os supermercados na oferta de alimentos orgânicos: apelando ao estilo de vida ego-trip. Ambiente \& Sociedade, v. 6, n. 2, 2003.

ILBERY, B. et al. Product, process and place an examination of food marketing and labelling schemes in Europe and North America. European Urban and Regional Studies, v.12, p.116-132, 2005.

ILBERY, B.; KNEAFSEY, M. Producer constructions of quality in regional speciality food production: a case study from south west England. Journal of Rural Studies, n. 16, p. 217-230, 2000.

LAURENT, F. Palestrante. Formas de desenvolvimento da agricultura e a alimentação: da escala internacional à escala local. 2013. Palestra realizada no Programa de Pós-Graduação em Desenvolvimento Rural/PGDR/UFRGS, Porto Alegre, 14 ago. 2013. 
MIELE, M. Consumption culture: the case of food. In: CLOKE, P.; MARSDEN, T.; MOONEY, P.H.

Handbook of Rural Studies. 2006.

PORTILHO, F.; CASTANEDA, M.; CASTRO,

I.R.R. A alimentação no contexto contemporâneo: consumo, ação política e sustentabilidade. Ciência \& Saúde Coletiva. v.16, n. 1, p. 99-106, 2011.

WISKERKE, J.S.C. On places lost and places regained: reflections on the alternative food geography and sustainable regional development. International Planning Studies, 2010. 